\title{
Erratum to: Chaotic masking of communication in an emitter-relay-receiver electronic setup
}

\author{
B. Nana - P. Woafo
}

Published online: 26 August 2016

(C) Springer Science+Business Media Dordrecht 2016

\section{Erratum to: Nonlinear Dyn (2015) 82:899-908 DOI 10.1007/s11071-015-2204-0}

In the original article, a typing error occurs in each second equation of the set of Eqs. (9)-(11). One should add $-s h\left(x_{1}\right),-s h\left(x_{2}\right)$ and $-s h\left(x_{3}\right)$, respectively, on each of these three equations as they are the copies of Eq. (7).

The results of the article remain the same as the simulations were carried out with the good equations.
The online version of the original article can be found under doi:10.1007/s11071-015-2204-0.

B. Nana $(\varangle)$

Department of Physics, Higher Teacher Training College, University of Bamenda, PO Box 39, Bamenda, Cameroon e-mail: na1bo@yahoo.fr

URL: http://www.lamsebp.org

P. Woafo

Laboratory of Modelling and Simulation in Engineering, Biomimetics and Prototypes, Faculty of Science, University of Yaounde I, PO Box 812, Yaounde, Cameroon
Acknowledgments We thank Viet-Thanh Pham and Sajad Jafari for pointing our attention on this error. 